\title{
Redescription of siluroid Catfish Pterocryptis barakensis Vishwanath \& Nebeshwar (Siluriformes: Siluridae)
}

\author{
W. Vishwanath ${ }^{1} \&$ K. Nebeshwar ${ }^{2}$ \\ 1, 2 Department of Life Sciences, Manipur University, Canchipur, Imphal, Manipur 795003, India \\ Email: ${ }^{1}$ vnath54@yahoo.co.in
}

Date of publication (online): 26 August 2009 Date of publication (print): 26 August 2009 ISSN $0974-7907$ (online) | 0974-7893 (print)

Editor: Rema Devi

Manuscript details:

Ms \# 01795

Received 31 May 2007

Final received 07 December 2007

Finally accepted 30 July 2009

Citation: Vishwanath, W. \& K. Nebeshwar (2009). Redescription of siluroid Catfish Pterocryptis barakensis Vishwanath \& Nebeshwar (Siluriformes: Siluridae). Journal of Threatened Taxa 1(8): 425-428.

Copyright: (c) W. Vishwanath \& K. Nebeshwar 2009. Creative Commons Attribution 3.0 Unported License. JoTT allows unrestricted use of this article in any medium for nonprofit purposes, reproduction and distribution by providing adequate credit to the authors and the source of publication.

Author Details: Dr. W. VISHWANATH is a Professor in the Department of Life Sciences, Manipur University. His field of specialization is fish and fisheries. He is at present engaged in taxonomy and systematics of freshwater fishes of northeastern India.

Dr. K. Nebeshwar is Project Fellow in a research project on catfish phylogeny of northeastern India funded by NBFGR (National Bureau of Fish Genetic Resources), Lucknow, an ICAR institute to Department of Life Sciences, Manipur University. $\mathrm{He}$ is well versed with fish taxonomy and is actively engaged in fish fauna exploration and description of new taxa in the region.

Author Contribution: The study: WV - Supervision of taxonomy and phylogeny of freshwater fishes of northeastern India, KN Morphometric study and identification of fish species. Current paper: WV - Supervised the work and helped in identifying the species, $\mathrm{KN}$ - Detailed examination of specimens and comparison with closely related species to establish the new species.

Acknowledgement: The authors are gratefu to ICAR-NATP (Indian Council of Agricultural Research's National Agricultural Technology Project) for financial assistance.
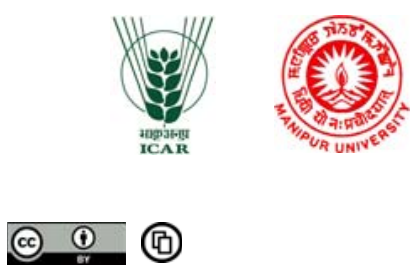

OPEN AGGESS | FREE DOWNLOAD
Abstract: Description of Pterocryptis barakensis from the Barak River, Tamenglong District (Brahmaputra drainage) of Manipur, India is inadequate. It is distinguished from $P$. berdmorei (Blyth) and the only other known species of the genus from the Indian region in having longer caudal fin, distinct sensory pores, serration pattern on posterior edges of anterior and posterior segments of pectoral spine, rounded tip and colour of pectoral and ventral fin, dimorphism in genital papillae in males and females and by a combination of meristic and morphometric characters.

Keywords: Manipur, Pterocryptis barakensis, redescription.

\section{INTRODUCTION}

Fishes of the genus Pterocryptis Peters are distinguished from other siluroids in having small dorsal fin, upper jaw longer than the lower jaw, and a confluent anal and caudal fin with a distinct notch between them (Bornbusch 1991). The species distributed in the Indian region are: P. gangelicus (Peters) of the Ganges; P. afghana (Gunther) of Afghanistan, type locality of which is doubtful (Day 1878; Shaw \& Shebbeare 1937; Menon 1999); $P$. indicus (Datta, Barman \& Jayaram) of Brahmaputra basin; P. roynaadensis (Day) of Western Ghats in Kerala, Cauvery and Tungabhadra river basins. Arunkumar \& Tombi (1997) described Silurus morehensis from Chindwin drainage basin in Manipur. Ng \& Freyhof (2001) considered the species to be a junior synonym of P. berdmorei and reported 16 nominal species under the genus.

Vishwanath and Nebeshwar (in Jayaram 2006) described Pterocryptis barakensis based on 19 specimens from Vanchengphai village, Barak drainage in Manipur. The description is not adequate. The paper gives a detailed description of the species, and its relationships with its congeners are also given.

\section{Materials and Methods}

Fish were collected from the Vanchengphai village using gill nets. The meristic and morphometric measurements followed the techniques of Jayaram (1999). Osteological study followed Kobayakawa (1989). For osteological study, 3 specimens were dissected and stained with Alizarin S following Hollister (1934). The description is based on formalin preserved specimens. Measurements were taken with digital calipers to $0.1 \mathrm{~mm}$. The number of specimens exhibiting a given count is indicated in parentheses. Fin ray counts and osteological studies were done using a zoom stereoscopic microscope.

\section{Pterocryptis barakensis Vishwanath \& Nebeshwar, 2006 (Image 1)}

Pterocryptis barakensis Vishwanath and Nebeshwar, In: Jayaram, 2006: 99-100 (type-locality: Barak River at Vanchengphai village, Manipur).

\section{Material examined}

Holotype: Male, $231 \mathrm{~mm}$ SL, Barak R. at Vanchengphai village, Tamenglong District, Manipur (MUMF-4018).

Paratypes: 18 ex., 128.0-227.3 mm SL, collection data as of holotype (MUMF 4000$4017)$.

\section{Diagnosis}

The species has the following combination of characters: elongated body and caudal fin, rudimentary dorsal fin with two rays or completely absent; body from head to caudalfin base with 12-16 transverse rows of sensory pores extending from mid dorsal region to 


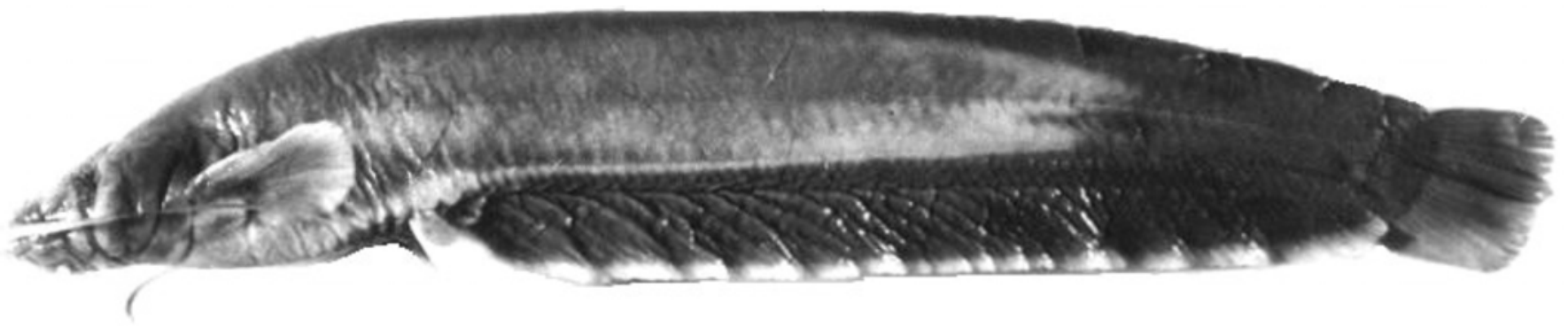

Image 1. Lateral view of Pterocryptis barakensis

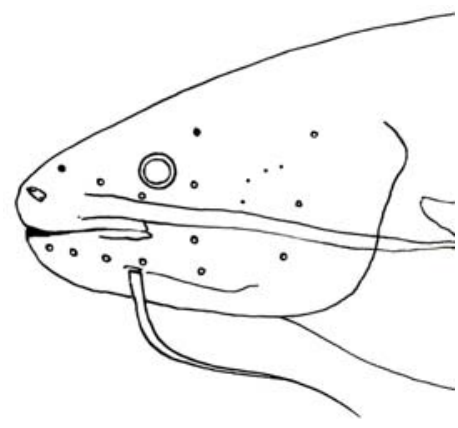

Figure 1. Arrangement of pores on head of $P$. barakensis

lateral line; 12 distinct sensory pores, arranged semicircularly on ventral surface of head extending from anterior sides of opercular region on either side to behind lower lip, outer margin of anal fin, ventral and pectoral fins white to pale white; pectoral fin with 14-15 rays, vomerine teeth band continuous.

\section{Description}

Dorsal fin absent or minute and soft with two rays, pectoralfin rays $I, 13-14$; pelvic-fin rays $i, 7-8$; anal fin rays $65-77$; caudal fin rays $6-7+8-9$; vertebrae $54-55$; branchiostegal rays 13. Body elongate, compressed behind head region. Head depressed. Upper jaw prominent and longer than lower jaw. Mouth inferior, gape of mouth narrow and semicircular, extends upto the region below anterior margin of orbit. Eyes covered with skin. Barbel two pairs, maxillary barbels extend beyond pectoral fin. In juveniles and in medium sized males (140-185 mm SL), maxillary barbels extend beyond ventralfin base. A single pair of mandibular barbel present, does not extend to pectoral-fin base. 12-16 transverse lines (vertical lateral line) of widely dotted sensory pores arranged in more or less unequal intervals from the posterior-most end of supraoccipital bone to the base of the caudal fin. A distinct horizontal lateral line is also present in addition to the usual vertical line. Variation in number of transverse lines of dotted sensory pores, 12-13 numbers in males and 15-16 in females. Caudal fin relatively very long and almost truncated. Anal fin long and confluent with caudal fin but with a distinct notch. Anal-fin base extends 1.52-1.64 times of standard length. Anterior nostrils tubular. Anterior margin of pectoral spine smooth, posterior margin granulated in one or two rows and in female posterior margin smooth. Dorsal fin rudimentary with two rays or completely absent.

The species has characteristic arrangement of pores on head (Fig. 1) as follows: (1) one row of 12 pores on the ventral surface behind lower lip, six on either of the mandibular region; (2) two sensory pores run vertically upward above the $1^{\text {st }}$ and $12^{\text {th }}$ pores of mandibular row; (3) one row each with three pores run vertically upward on post-orbital region towards the anterior region of the frontal, behind the eye; (4) one row of four pores run obliquely on mesethmoid region towards the tip of head; (5) two pores on middle region of the frontal behind the frontal pores; (6) two tubercle like structures with pores between the anterior nostrils; (7) three pores on each side of the head in the posterior region of frontal; (8) three canals, one each on preopercle, inter-opercle and opercle run towards hyomandibular region.

\section{Colour}

Body grayish brown to dirty yellowish-brown or light grayish-white on dorsal surface; light brown to dirty white on ventral surface. Outer margin of anal fin white. Half length of ventral fin light grayish-white or white in colour. 3/4 length of pectoral fin white or light grayish-white. Dotted sensory pores above the lateral line white in colour.

\section{Sexual dimorphism}

Males are different from females in having pointed and elongated genital papilla vs. rounded one; posteriorly granulated pectoral spine vs. smooth one; shorter caudal-fin base, pectoral-fin base, caudal peduncle; shallower body; shorter pre-anal length and mandibular barbel length.

\section{Osteology}

Three specimens were dissected for osteological study.

Skull (Fig. 2a \& b): Lateral process of lateral ethmoid prominent; lateral process of mesethmoid remarkably long and slender; mesethmoid narrow at base of its lateral process; sagittal crest confined from middle part to posterior part of supraoccipital pterotic and epioccipital bones project outward, sensory canals on frontal bone forming a mere groove.

Suspensorium (Fig. 3a \& b): Metapterygoid small compared with hyomandibular, metapterygoid process well developed; hyomandibular process well developed forming a pterygoid process, an elongated and sheet-like bone separates from metapterygoid bone, quadrate process poorly developed.

Shoulder girdle (Fig. 4a \& b): Vertical part of cliethrum short, ventral coracoid lamina poorly developed, coracoid connected with cliethrum by complex suture.

Caudal skeleton: All hypural bones separated from each other, hypurapophysis absent, secondary hypurapophysis forming a well-developed shelf on hypural 1 only. 
Table 1. Morphometric data of Pterocryptis Barakensis

\begin{tabular}{|c|c|c|c|c|c|c|c|c|}
\hline \multirow[b]{3}{*}{ Standard length } & \multicolumn{2}{|c|}{ Holotype } & \multicolumn{6}{|c|}{ Paratypes } \\
\hline & \multirow{3}{*}{$\begin{array}{l}\% \text { SL } \\
231.0 r\end{array}$} & \multirow[t]{2}{*}{$\% \mathrm{HL}$} & \multicolumn{3}{|c|}{$\% S L$} & \multicolumn{3}{|c|}{$\% \mathrm{HL}$} \\
\hline & & & $128.0-227$ & & & & & \\
\hline & & & Range & Mean & SD & Range & Mean & SD \\
\hline Body depth & 14.55 & 82.96 & $13.5-16.3$ & 14.7 & & $75.1-97.0$ & 85.3 & 5.90 \\
\hline Caudal length & 9.18 & 52.35 & $7.6-10.2$ & 8.8 & 0.6 & $45.7-58.6$ & 51.0 & 3.20 \\
\hline Head length & 17.53 & & 16.3-18.3 & 17.3 & 0.5 & & & \\
\hline Head height at occiput & 9.96 & 56.79 & $9.8-10.8$ & 10.1 & 0.3 & $56.1-63.3$ & 58.6 & 2.30 \\
\hline Snout length & 7.14 & 40.74 & $6.5-7.5$ & 7.1 & 0.3 & $39.1-4.2$ & 41.0 & 0.76 \\
\hline Eye diameter & 1.52 & 8.64 & $1.4-1.6$ & 1.5 & 0.1 & $8.2-9.5$ & 8.7 & 0.30 \\
\hline Inter-orbital space & 9.31 & 53.09 & $8.1-9.7$ & 9.0 & 0.4 & $48.6-54.8$ & 52.1 & 0.02 \\
\hline Length of caudal peduncle & 3.38 & 19.26 & $3.1-4.5$ & 3.6 & 0.4 & $17.4-27.1$ & 20.7 & 2.34 \\
\hline Height of caudal peduncle & 7.01 & 40.2 & $5.9-7.6$ & 6.5 & 0.5 & $34.7-44.3$ & 37.6 & 2.66 \\
\hline Pre-dorsal length & 24.99 & & $23.9-26$ & 24.9 & 0.6 & & & \\
\hline \multicolumn{9}{|l|}{ Dorsal fin length } \\
\hline \multicolumn{9}{|l|}{ Dorsal fin height } \\
\hline Pectoral length & 11.34 & 64.69 & $10.5-12.0$ & 11.2 & 0.4 & $60.7-70.0$ & 64.9 & 2.00 \\
\hline Ventral length & 7.14 & 40.74 & $6.3-7.9$ & 7 & 0.5 & $35.5-44.9$ & 40.5 & 2.65 \\
\hline Anal fin length & 65.8 & & $61.2-76$ & 63.6 & 1.5 & & & \\
\hline Maxillary barbell & 28.14 & & $26.7-36.7$ & 30.0 & 2.4 & & & \\
\hline Mandibular barbell & 9.96 & 56.79 & $8.7-12.1$ & 10.3 & 0.8 & $47.6-69.8$ & 60.0 & 4.90 \\
\hline Head length at occiput & 13.2 & 75.31 & $12.6-14.4$ & 13.5 & 0.6 & $74.8-83.0$ & 78.0 & 2.20 \\
\hline Head height at eye & 6.93 & 39.51 & $6.2-7.3$ & 7.0 & 0.2 & $37.4-42.0$ & 40.5 & 1.34 \\
\hline Head width at eye & & 11.47 & $10.1-12.0$ & 11.3 & 0.5 & $60.9-70.0$ & 65.5 & 2.13 \\
\hline Head width at neck region & & & $12.4-14.1$ & 13.4 & 0.5 & $74.0-80.0$ & 77.9 & 2.10 \\
\hline Body width at dorsal fin origin & 12.16 & 69.38 & $11.1-14.4$ & 12.7 & 1.0 & $62.2-87.0$ & 73.6 & 7.20 \\
\hline Body width at anal fin origin & 9.74 & 55.56 & $9.1-11.0$ & 9.7 & 0.5 & $50.9-64.5$ & 56.5 & 3.50 \\
\hline Pre-ventral length & 30.39 & & $30.5-34.7$ & 33.0 & 1.2 & & & \\
\hline Pre-anal length & 33.17 & & $33.5-38.8$ & 36.3 & 1.5 & & & \\
\hline Pre-anus length & 32.03 & & $32.2-35.6$ & 34.4 & 1.1 & & & \\
\hline Body depth at anal fin origin & 13.85 & 79.01 & $13.7-15.4$ & 14.4 & 0.5 & $75.8-90.0$ & 83.8 & 3.76 \\
\hline Inter-nasal distance (anterior) & 4.16 & 23.7 & $3.8-4.5$ & 4.1 & 0.2 & $21.8-24.5$ & 23.5 & 0.83 \\
\hline Inter-nasal distance( posterior) & 4.24 & 24.2 & $4.3-4.8$ & 4.5 & 0.2 & 24.0-27.9 & 26.1 & 0.96 \\
\hline Mouth gap width & 10.82 & 61.73 & $9.4-11.5$ & 10.5 & 0.5 & $56.3-62.9$ & 60.8 & 1.63 \\
\hline Caudal fin base length & 8.65 & 49.38 & $6.1-8.9$ & 7.5 & 0.8 & $36.9-52.9$ & 43.4 & 4.57 \\
\hline Ventral fin base length & 3.9 & 22.22 & $3.0-4.4$ & 3.6 & 0.4 & $17.0-25.7$ & 21.1 & 2.32 \\
\hline Pectoral fin base length & 4.33 & 24.69 & $3.7-4.7$ & 4.1 & 0.3 & $21.0-26.6$ & 23.9 & 1.52 \\
\hline Distance betn vent \&anal fin & 1.65 & 9.38 & 1.8-3.2 & 2.3 & 0.4 & 10.4-19.1 & 13.3 & 2.79 \\
\hline Distance between vent \& ventral fin & 2.81 & 16.05 & $2.4-3.1$ & 2.8 & 0.2 & 14.1-18.6 & 16.1 & 1.38 \\
\hline Distance between anterior \& posterior nostrils & 2.6 & 14.81 & $2.4-2.9$ & 2.6 & 0.1 & 14.4-16.7 & 15.2 & 0.58 \\
\hline
\end{tabular}

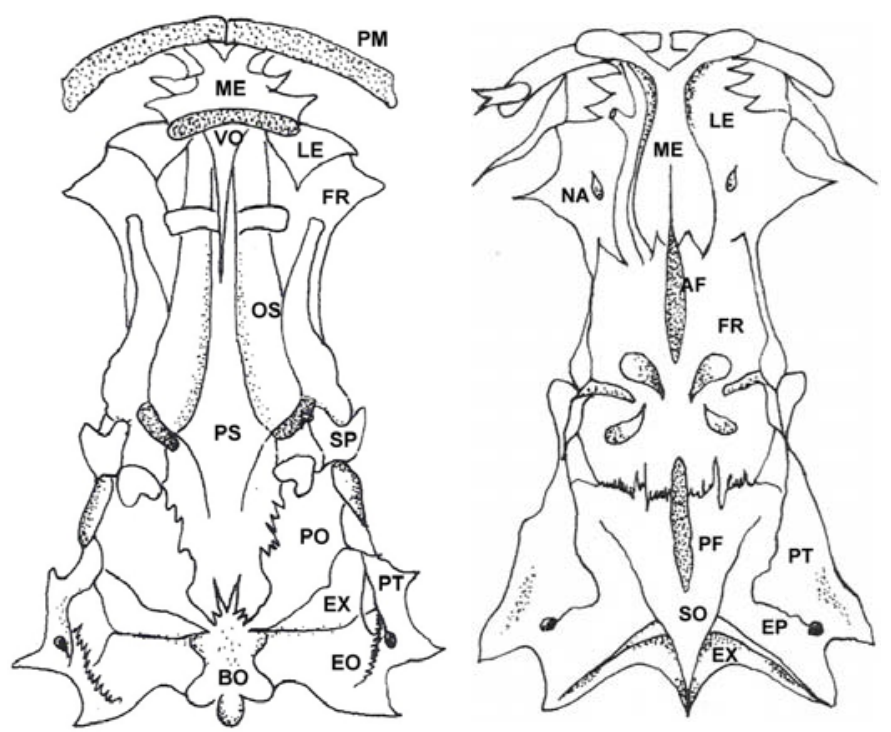

Figure 2. Skull of Pterocryptis barakensis

a - dorsal view; b - ventral view; LE - lateral ethmoid; ME mesethmoid; NA - nasal; AF - anterior fontanel; FR - frontal; PF - posterior fontanel; SO - supraoccipital; PT - pterotic; EP - epioccipital; EX - exoccipital; PM - premaxilla;

VO - vomer; OS - orbitosphenoid; PS - parasphenoid; PO - pro-otic; BO - basioccipital.

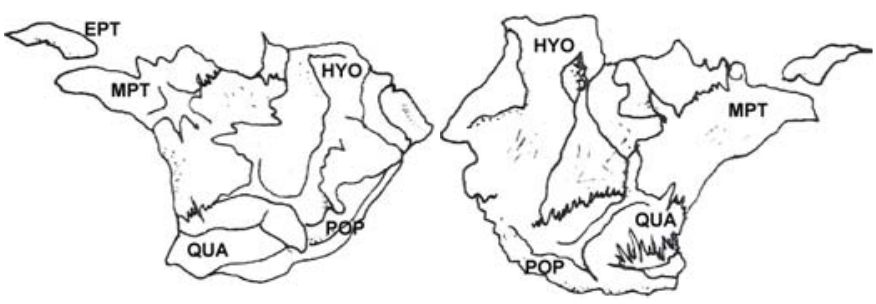

Figure 3. Suspensorium of Pterocryptis barakensis MPT - metapterygoid; EPT - endopterygoid;

HYO - hyomandibular; POP - preopercular; QUA - quadrate

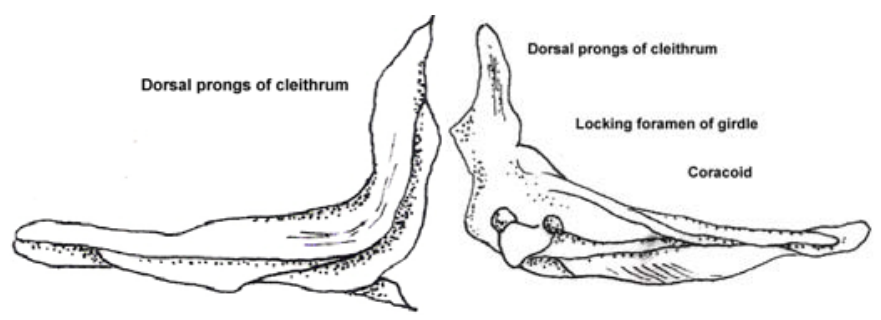

Figure 4. Shoulder girdle of Pterocryptis barakensis 

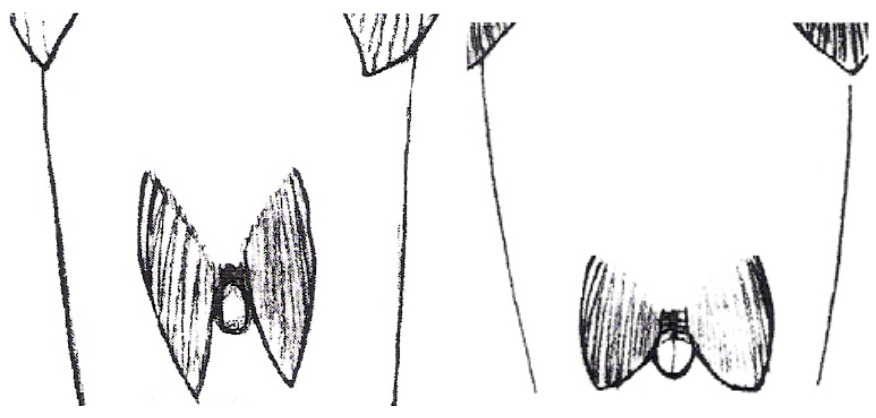

Figure 5. Shapes of pelvic fins in A. Pterocryptis morehensis and B. P. barakensis

\section{Etymology}

The species has been named after the river Barak from where it has been collected.

\section{Distribution}

Barak River, Vanchengphai village, Tamenglong district, Manipur, India.

\section{Remarks}

This new species is distinct from Silurus morehensis Arunkumar \& Tombi (1997) in its rounded pelvic fin vs. pointed (Fig. 5); not very distinct notch between anal and caudal fins vs. a very distinct notch; a line of distinct pores in mandibular region with two dorsally directed pore lines from its extremities vs. indistinct pore line without dorsally directed lines; three pore lines obliquely directed towards hyomandibular vs. two lines. The pores are prominent and more regularly arranged in $S$. barakensis (Fig. 1). The species under description is also different from $S$. torrentis Kobayakawa in having 0-2 rays on dorsal fin vs. 2-3 rays; 1-2 rows of finely granulated spines on posterior side of pectoral fin vs. posteriorly serrated one; shorter predorsal length (23.9-26.0 vs. $27.8 \% \mathrm{SL})$.

This new species is also distinct from $S$. cochinchinensis (as described by Kobayakawa 1989) in having a well developed sagittal vs. no crest, Cliethrum and ventral part of coracoid connected by a complex suture vs. simple suture, lateral line with both vertical and horizontal pores vs. vertical pores, posterior surface of pectoral spine in males granulated in one or two rows vs. serrated, vomerine teeth band continuous vs. separated into a pair of small patches, maxillary barbels extend beyond pectoral fin vs. not reaching tip of pectoral fin and mandibular barbels exceed the head length vs. not exceeding head length.

An uncatalogued specimen in the Zoological Survey of India, Kolkata, measuring $161 \mathrm{~mm}$ SL, labelled as Silurus cochinchinensis, collected from Andhra Pradesh on 23.xii.1983 was examined for comparison with the new species. As the specimen did not have the characters as of the label, no comparison could be done.

In the revision of the genus Silurus, Kobayakawa (1989) included 17 species. Silurus wynaadensis Day (now Pterocryptis) is found in the Western Ghats. Eschmeyer (1990) and Menon (1999) considered Pterocryptis Peters (1861) a synonym of the genus Silurus Linnaeus. However, Bournbusch (1991) removed Pterocryptis from synonymy with Silurus. Identity of Silurus cochinchinensis reported by Hora (1936) from Barak basin in
Manipur and also that reported by Shaw \& Shebbeare (1937)

from Western Duars, northern Bengal, needs verification.

\section{References}

Arunkumar, L. \& H. Tombi (1997). Silurus morehensis, a new species of siluroid catfish (Order: Siluriformes, Family: Siluridae) from Manipur, India. Journal of Freshwater Biology 9(2): 72-76.

Bornbusch, A.H. (1991). Redescription and reclassification of the silurid catfish Apodoglanis furnessi Fowler (Siluriformes: Siluridae), with diagnoses of three intrafamilial silurid subgroups. Copeia 1991: 1070-1084.

Day, F. (1878). The Fishes of India: Being a Natural History of the Fishes Known to Inhabit the Seas and Fresh Waters of India, Burma and Ceylon. William Dowson \& Co., London, 778pp.

Eschmeyer, W.N. (1990). Catalogue of the Genera of Recent Fishes. California Academy of Sciences. San Francisco, 697pp.

Hollister, G. (1934). Clearing and dying fishes for bone study. Zoologica 12: $89-101$.

Hora, S.L. (1936). On a further collection of fish from the Naga hills. Records of Indian Museum 38: 317-331.

Jayaram, K.C. (1999). The Freshwater Fishes of Indian Region. Narendra Publishing House, New Delhi, 455pp.

Jayaram, K.C. (2006). Catfishes of India. Narendra Publishing House, New Delhi, 383pp.

Kobayakawa, M. (1989). Systematic revision of the Catfish Genus Silurus, with description of a new species from Thailand and Burma. Japanese Journal of Ichthyology 36(2): 155-186.

Menon, A.G.K. (1999). Checklist - Fresh Water Fishes of India, Zoological Survey of India, Occasional Paper 175, 366pp.

Ng, H.H. \& J. Freyhof (2001). A review of the catfish genus Pterocryptis (Siluridae) in Vietnam, with the description of two new species. Journal of Fish Biology 59: 624-644.

Peters, W. (1861). Über zwei newe Gattungen von Fishchen aus dem Ganges. Monatsberichte der Koniglichen Preussischen Akademie der Wissenschaften Zu Berlin: 712-713.

Shaw, G.E. \& E.O. Shebbeare (1937). The fishes of Northern Bengal, Journal of Asiatic Society, Bengal 3: 1-137.

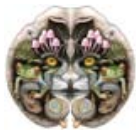

